\title{
Religiosity, masculinity, and marital satisfaction among Javanese Muslim men
}

Wade, Jay C. $\bowtie$

Fordham University, USA (jcarlylewade@ gmail.com)

Wiloso, Pamerdi Giri

Satya Wacana Christian University, Indonesia (girindra_abhiyoga@yahoo.co.id)

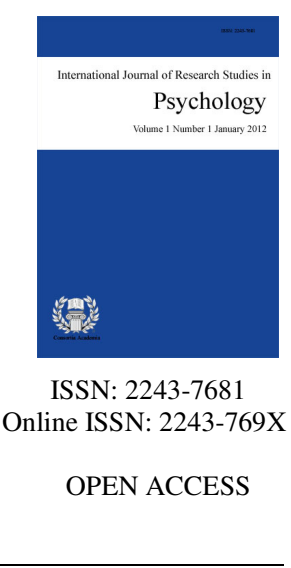

Received: 21 February 2016

Revised: 9 April 2016 DOI: $10.5861 /$ ijrsp.2016.1468

Accepted: 1 May 2016

\begin{abstract}
This exploratory study describes Javanese Muslim men's definitions of masculinity or manhood. The research study involved interviewing key informants, group interviews with Javanese men, and survey research. In this sequential mixed-methods research design, the construct of masculinity was operationalized and relationships between religiosity, masculinity, and marital satisfaction and harmony were explored. Men's perceptions of the changing gender roles in Javanese society were also examined as they relate to marital satisfaction. Masculinity experiences were rated for their importance and included head of family responsibilities, being strong, constructive relationships with others, and constructive mental activity. The survey research showed religiosity related positively to the importance of the masculinity experiences, marital satisfaction, and marital harmony, and the positive relationship between religiosity and marital satisfaction was mediated by the importance of masculinity experiences. The findings are discussed within the context of Javanese culture.
\end{abstract}

Keywords: Javanese Muslim men; masculinity; marital satisfaction; religiosity; gender roles 


\section{Religiosity, masculinity, and marital satisfaction among Javanese Muslim men}

\section{Introduction}

Java has a population of about 140 million people of which $70 \%$ are of Javanese ethnicity and the majority identify as Muslim (Encyclopedia Britannica, n. d.). In the past twenty years in Indonesia there has been an increase in divorce rates, which previously were lower when compared to Western societies (Cammack \& Heaton, 2011). As such, there is concern about the breakdown of the family and the consequences of divorce for individuals and society. Since democratic reforms were introduced after the fall of autocratic president Suharto in 1998, commensurate emancipation in the role of women appears to have contributed to a sharp, inadvertent rise in divorce rates that is not limited to Java, but has been observed across Indonesia (IANS, 2009). According to Nasaruddin Umar, Director in the Indonesian Ministry of Religious Affairs, the majority of divorces were caused by general family disharmony and most of the divorces have been initiated by women (IANS, 2009). Cammack, Bedner, and van Huis (2015) noted that Muslim men and women filed for divorce in equal numbers in 1996-1997, and that every year thereafter more divorces were initiated by women such that by 2011 women accounted for $69 \%$ of all cases filed.

Several scholars have speculated on the causes for the upturn in divorce rates and in the increase in women initiating divorce. As previously mentioned, women's emancipation has been suggested as a contributing factor to changes in divorce behavior. The political transition that occurred with the end of Suharto's rule had the effect of Indonesian women becoming more assertive in the exercise of their rights (Cammack et al., 2015). Concomitantly, after the mid-1990s there was a sharp rise in exposure to media portrayals reflecting a "modernist" Islamic view on a wife's role and gossip programs about the lives of celebrities where divorce was commonplace (Jones, 2015). Adamson (2007) argued that towards the end of Suharto's rule until the present day there has been the concern of women not needing men, which has been in concert with changes occurring in Indonesia with regard to increasingly becoming part of a global economic system and new educational and work opportunities for women. Thus, cultural anxiety about the breakdown of the family became associated with increasing Western influences and changing gender roles.

Indonesia's commitment to gender equality and women's empowerment is represented in national policy as early as 1978 with the establishment of the Ministry of the Status and Role of Women, and at the international level with the ratification of the UN Convention on the Elimination of all Forms of Discrimination against Women (CEDAW) in 1984. By 2000, a landmark Presidential Decree required all government agencies to implement gender mainstreaming strategies in their policies, programs, and budgets to actualize gender equality and justice in the family. Hayati, Emmelin, and Eriksson (2014) have contended that these changes in national policy have challenged cultural values for men and women, having implications for the relationship between men and women in society. They noted that the Indonesian Marriage Law is not aligned with national policy. Although the Marriage Law adopts the principle of equality between husband and wife in the family and in society, it specifies that the husband is the head of the family and the wife is the mother of the household; the husband has the responsibility to protect his wife and support her to the best of his abilities, and the wife has the responsibility of managing the household to the best of her abilities (Law of the Republic of Indonesia Number 1 of the Year 1974 on Marriage, 1974). Hayati et al. noted these marital and gender roles are deeply rooted in Islamic religious culture and contradict national policy, becoming a source of ambiguity for Indonesians in the daily practice of sustaining marital relationships. Furthermore, these changes in society have an effect on men's roles, "causing ambiguity regarding the ideal self as a man according to the religious values and the real self as a man in the current sociopolitical climate" (p. 10).

These "recent social and political developments have ensured that the question of men in Indonesian gender studies has assumed a greater sense of urgency" (Clark, 2010, p. 28). Therefore, research that elucidates the 
effect of changing gender roles on the lives of Javanese Muslim men will serve to better understand and address issues critical to the personal lives of Javanese men and women.

\subsection{Javanese culture}

From a social constructionism perspective, gender roles are learned and culturally and socially determined. "How gender roles have evolved in different cultures is largely tied to the core values of those cultures" (Nwaba, 2014, para. 1). As such, to understand traditional Javanese gender roles it is important to understand the major elements of Javanese culture. These elements can be characterized in terms of harmony in social relations, respect for higher-ranking persons, benevolence and responsibility for those in lower positions, and care and concern for others.

Albert, Trommsdorff, Mayer, and Schwarz (2005) and Megawangi, Zeitlin, and Colletta (1995) have provided descriptions of Javanese culture based on the anthropological literature. These authors noted that harmony is the most important value in human relationships, and all overt expressions of conflict should be avoided. The individual serves as a harmonious part of the family or group, and one's life in society should be characterized by rukun (harmonious unity). In addition, the harmonious family is a building block for constructing a harmonious society. Consistent with harmony in relations with others is the hierarchical organization of social relations (hormat). Everyone should know their place and responsibilities: honor and respect is shown to those in higher positions, while for those in lower positions one shows benevolence and has a sense of responsibility for their welfare. Thus, parents and the elderly are to be respected and honored, whereas compassionate and paternalistic behavior is shown towards children, subordinates (e.g., employees), and those of lower social status. Within the community there is care and concern for others reflected in the principle of gotong royong. Good relations and sharing with one's neighbors is expected, which involves mutual help among neighbors or the sharing of burdens. This community behavior exists among all classes. Thus, Javanese society is communal and its culture is collectivist in which the cultural value of group harmony underlies interpersonal relationships.

\subsection{Traditional Javanese gender roles}

The literature on traditional Javanese gender roles indicates both rigidity and flexibility of familial and parental roles. According to Williams (1991), men are the head of the family and women manage the household and care for the children, with clearly designated areas of men's and women's work. However, the husband and wife fulfill complementary roles regarded as traditional responsibilities, working together as a team and having equal partnership. Often, women provide economic support to the family through outside employment and control the family finances. Men will participate in child-rearing, and if it is necessary will perform household tasks. In a qualitative study on the fathering that Javanese university students had received, five themes of fathering were identified: fulfilling emotional needs, fulfilling physical needs, giving direction, giving good care, and fully sacrificing (Wirawan \& Ratnaningsih, 2011).

Hayati et al. (2014) provided a more nuanced description of marital roles as compared to Williams (1991). They conducted focus groups with 44 men who were local community leaders from a Central Java province in order to obtain their views on masculinity and using violence as a means of resolving marital conflict. The researchers identified three different perspectives of masculinity: traditionalist, pragmatist, and egalitarian. All three perspectives on masculinity held the Koran to be the basic reference for their views on marital roles and each differed with respect to the acceptance of violence against the wife. The traditionalist view is one in which the man is responsible for earning a living and the woman can only be responsible for childcare and household maintenance. This division of roles in the family is important, and such men are against the women empowerment programs of the Indonesian government. Wife abuse is considered acceptable in certain situations. The pragmatist view considers marital roles as complementary to each other in managing the family life, and being a man involves having positive qualities in one's role as the family guardian. Although marital roles are 
more flexible, "wife abuse" is considered acceptable. The egalitarian perspective views marriage as a joint effort in achieving aspirations for the family, and there is no strict or fixed marital roles. Men recognize that women have equal opportunities for public participation and their capabilities should be utilized for the wellbeing of the family. Wife abuse is considered unacceptable and avoidable. The egalitarian perspective accepts the changes in society that have occurred with regard to gender roles.

Within Indonesia more generally, there has been improvement in the emancipation era in key areas related to gender inequality, in particular with regard to gender parity in education and women's workforce participation (Garcia, Greenley, Martin-Onraët, \& Pollack, 2015). However, Turner (2002) noted how women may experience contradictory or dual gender ideologies in which they are encouraged to participate in economic development yet must not neglect their roles as wives and mothers. She referred to the Government's promotion of Panca Dharma Wanita (Five Duties of Women) as an example of how women's gender roles include both economic and domestic aspects. The "five duties require women to be 1) loyal companions of their husbands, 2) managers of their households, 3) educators and guiders of their children, 4) supplementary wage earners for their families, and 5) useful members of their communities" (pp. 91-92). For men, the Government defines men's roles as “the family's primary earner and the family's public representative in all political, social, and religious affairs” (p. 92). These changes and seemingly contradictory gender roles for women may have an effect on men as well, in particular with regard to enacting familial roles and their marital satisfaction.

\subsection{The current study}

The current study is an extension of Marshall Clark's cultural analysis of constructions of the masculine in contemporary Indonesian society. In his book, Maskulinitas: Culture, Gender and Politics in Indonesia, Clark (2010) argued for the relevance of increased attention to the subject of men and masculine identity in Indonesia in a post-authoritarian Indonesia. Given there has been no prior research on Javanese men, this exploratory study sought answers to the following research questions:

1. How do Javanese men define masculinity/manhood?

2. What is the relationship between men's perception of changing gender roles and their marital satisfaction?

3. What is the relationship between masculinity and marital satisfaction?

4. What is the relationship between religiosity and masculinity?

5. What is the relationship between religiosity and men's marital satisfaction?

To achieve this aim, the research design was both qualitative and quantitative. We used a sequential mixed-methods strategy that involved collecting data in an iterative process, whereby the data collected in one phase contributed to the data collected in the next (See Figure 1). The qualitative study involved conducting group interviews with Javanese Muslim men to collect substantive data on their experiences and perspectives on manhood. The quantitative study was descriptive research conducted with Javanese Muslim men that investigated correlates of marital satisfaction. In particular, we examined masculinity, religiosity, and perceived change in gender roles as correlates.

\section{Qualitative study}

\subsection{The researchers}

The first author was the principal investigator who received a Fulbright Senior Research Scholar Award to conduct research on marital and life satisfaction among Indonesian men. He lived in Salatiga, Java for three months where the research was conducted. The implementation of the research project had three phases. The initial phase involved one month of direct observation and reading articles on Javanese history and culture as an approach to understanding Javanese culture and gender roles. The second phase involved interviewing two key informants and conducting group interviews with Javanese men. The third phase involved conducting survey 
research. The research was approved by the Fordham University Institutional Review Board (IRB) and the State Ministry of Research and Technology, Jakarta, Indonesia.

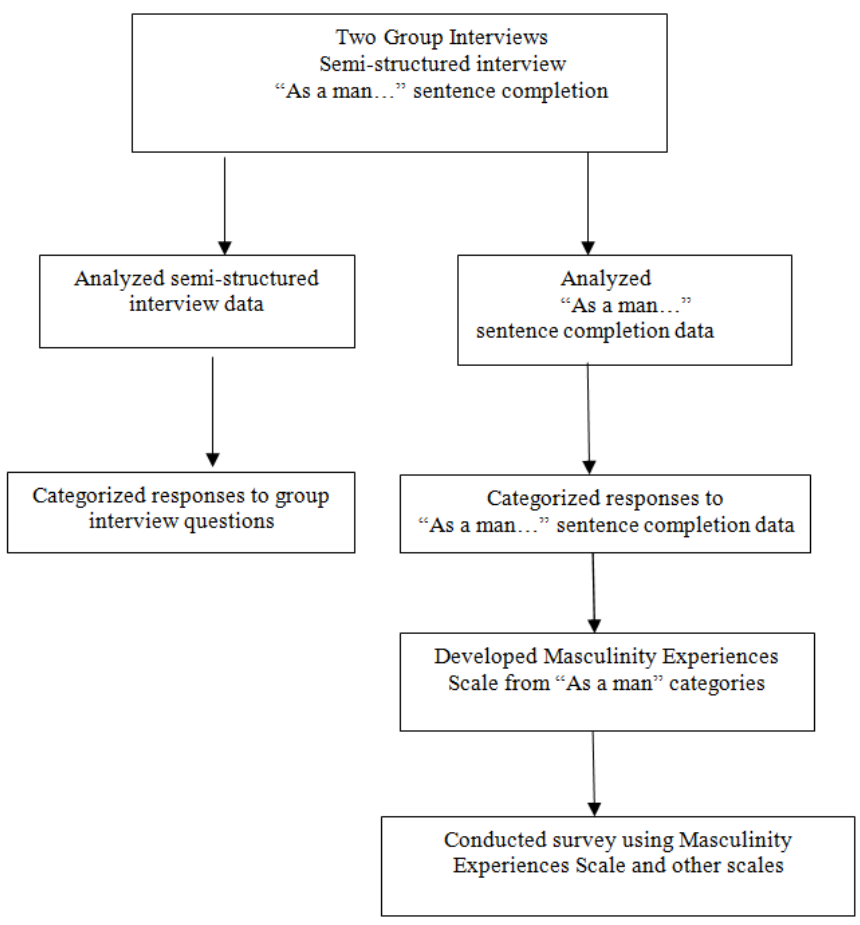

Figure 1. Sequential mixed methods data collection strategy

The collaborator on the research project was the co-author, a university professor with a doctorate in social anthropology. He is Javanese and Christian. There were several meetings throughout the project in which the researchers discussed the implementation of the project and differences in Javanese and American or Western cultures.

\subsection{Research design}

Direct observation and key informant interviews were the initial approaches to understanding the culture of Java; in particular, religion, history, societal norms, traditional gender roles, changes in gender roles, and how manhood is defined and experienced. The principal investigator observed Javanese men and women in work, home, and leisure settings and interacted with Javanese men that sometimes included informal interviews. The key informants were the co-author and a female professor at the university who has a doctorate in agriculture and economics and conducts research on gender and industry. She is Christian, half Javanese and half Sumbanese, and is involved in the women's movement and Women's Studies at the university. These semi-structured interviews were conducted in English and concerned questions related to Javanese culture, gender roles, and the effects of changing gender roles on Javanese families and society.

The researchers met on two occasions to discuss the setting, structure, and content for the group interviews. The purpose of the group interview is to systematically question several individuals simultaneously, in formal or informal settings (Fontana \& Frey, 1994). A group interview differs slightly in purpose from a focus group. In group interviewing the emphasis is on questions and responses between the researcher and participants, whereas the emphasis in focus groups is the interaction within the group based on topics supplied by the researcher (Kitzinger, 1994; Morgan, 1997). Given the language differences between the principal investigator and group participants, the researchers agreed that a format that allowed for questions and answers would best suit the needs for collecting data. The researchers also agreed that it would be appropriate for the principal investigator to give the participants remuneration in the amount of 100,000 IDR (approximately \$10 USD). 


\subsection{Participants}

The second author and a Javanese research assistant recruited the participants for the group interview by asking men they knew if they would like to be involved in a research project on Javanese Muslim men. Two group interview sessions were held that included a total of 12 participants. All participants lived in Salatiga, Java, which is located in Central Java and has a population of approximately 178,000 (Indonesia Database for Policy and Economic Research, World Bank, 2013). Participants' ages ranged from 22 to 43 years old as follows: 20s (8), 30s (1), and 40s (3). Five of the 12 participants were married. Three participants were students, and the working men had the following occupations: architect, bank officer, business owner (small restaurant, printing company), journalist, English teacher, engineering/construction, farming, and sales.

\subsection{Data collection}

The group interviews were co-led by the researchers and held in the home of the second author. The interviews were conducted in Indonesian and the co-author performed the translations. The principal investigator asked pre-set questions, and at times the co-author would assist participants in elaborating on their answers. Questions asked at the beginning of the group were developed to get the participants comfortable with the experience of disclosing to the researchers and others in the group. As such, each member of the group was first asked to tell their name, where they are from in Java, and anything about their family. The next set of questions were designed to have the men talk about the kinds of things men do and what they have observed, rather than asking them to focus on themselves. In this way, the men were the principal investigator's observers, so to speak, and their descriptions would not be filtered by their self-concepts. As the men became more comfortable talking in the group the questions were designed to have them describe their own lives.

Prior to beginning the group interview, the principal investigator introduced himself and told the group about his background and reasons for conducting the study. He asked for permission to audiotape the session and provided contact information. The men were then asked to complete a questionnaire that was provided in Indonesian with an English translation. (Details on the questionnaire are provided in the description of the survey study.) In particular, the participants completed a sentence completion task in which they were given the following instructions: "Please describe your personal experience of what it means to be a man by completing the following sentence, 'As a man ...' 10 times. Just give 10 different responses. Respond as if you were giving the answers to yourself, not to somebody else. There are no right or wrong responses. Simply write down the first thoughts that come to your mind." Underneath the instructions, "As a man " was provided ten times. These responses were used as qualitative data to inform the development of a measure that was used in the quantitative phase of the research project.

\subsection{Results}

The principal investigator analyzed the data from notes taken during the sessions and the audiotape of the sessions. All responses for each question were first listed with that question. When responses were similar, the one response that best characterized the responses was selected. The list of responses was then interpreted to provide a summary interpretation of the responses. The researchers and research assistant met to review the principal investigator's results and discuss their accuracy. Participant's responses to the interview questions are provided in Table 1 . The summary interpretation is provided below.

First, participants were asked to "Tell me about the man who has been the greatest influence on you." After they responded to this question they were next asked to "Describe men you have met or you know that you would not want to be like." By describing men who have had an influence on them they were describing the Javanese masculine ideal - men who represent the good qualities of manhood. They were also describing their male reference group, in most situations, or male role model, in that the question asks for them to identify a man. Such men taught values, were religious, and/or were responsible fathers. Men they identified who had a positive 
influence on them were one's father, a spiritual teacher, and Muhammad. Their responses were consistent with Javanese cultural values related to the importance of men's roles and behaviors within the family. Such characteristics of manhood included being the breadwinner, disciplined, protective of family, leader of family, accountable, and democratic. In describing men they did not want to be like, participants were describing the opposite of manhood or the qualities of manhood they reject. Their responses identified particular men; some were political leaders (e.g., Prime Minister of Israel, President of Syria) and others were men who they knew personally (e.g., friend, father, neighbor). Political leaders were cruel, tyrannical, or anti-Islamic. Men they knew personally were treacherous or irresponsible, or they abused substances, women, or social welfare. In general, such negative qualities of men were contrary to the Javanese cultural values of harmony in social relations and care and concern for others.

Participants were next asked, "What situations or experiences in your life have contributed to you feeling like a man?" By describing experiences that made them feel like a man the men were describing the cultural tenets of Javanese manhood. Manhood means taking on family responsibilities: leading and protecting the family, and working hard and providing for the family. Additionally, being independent makes one feel like a man. Fulfilling these tenets makes one feel like a man because they are fulfilling the male gender roles of Javanese society. By doing so, there is continuity between the actual (masculine) self and ideal (masculine) self within a cultural context.

The last two questions asked, "What particularly enjoyable experiences in your life have been related to being a man?" and "What particularly difficult experiences in your life have been related to being a man?" By describing enjoyable and difficult experiences in their life related to being a man the participants described the meaning of manhood and masculinity. Most of the enjoyable experiences involved activities or events in which there was a sense of achievement, where they were successful in accomplishing what they set out to do. In this regard, masculinity is defined through personal success, and it should be noted that success was not relative to competing with others. One experience was related to becoming a father, which may have included a sense of achievement among many other feelings that would be associated with the birth of one's children. Comparatively, most of the difficult experiences (four of the six) involved activities or events in which there was a sense of failure or inability to be successful. Examples of such experiences pointed to financial, familial, and interpersonal aspects of a man's life.

\section{Table 1}

Summary of Responses to Group Interview Questions

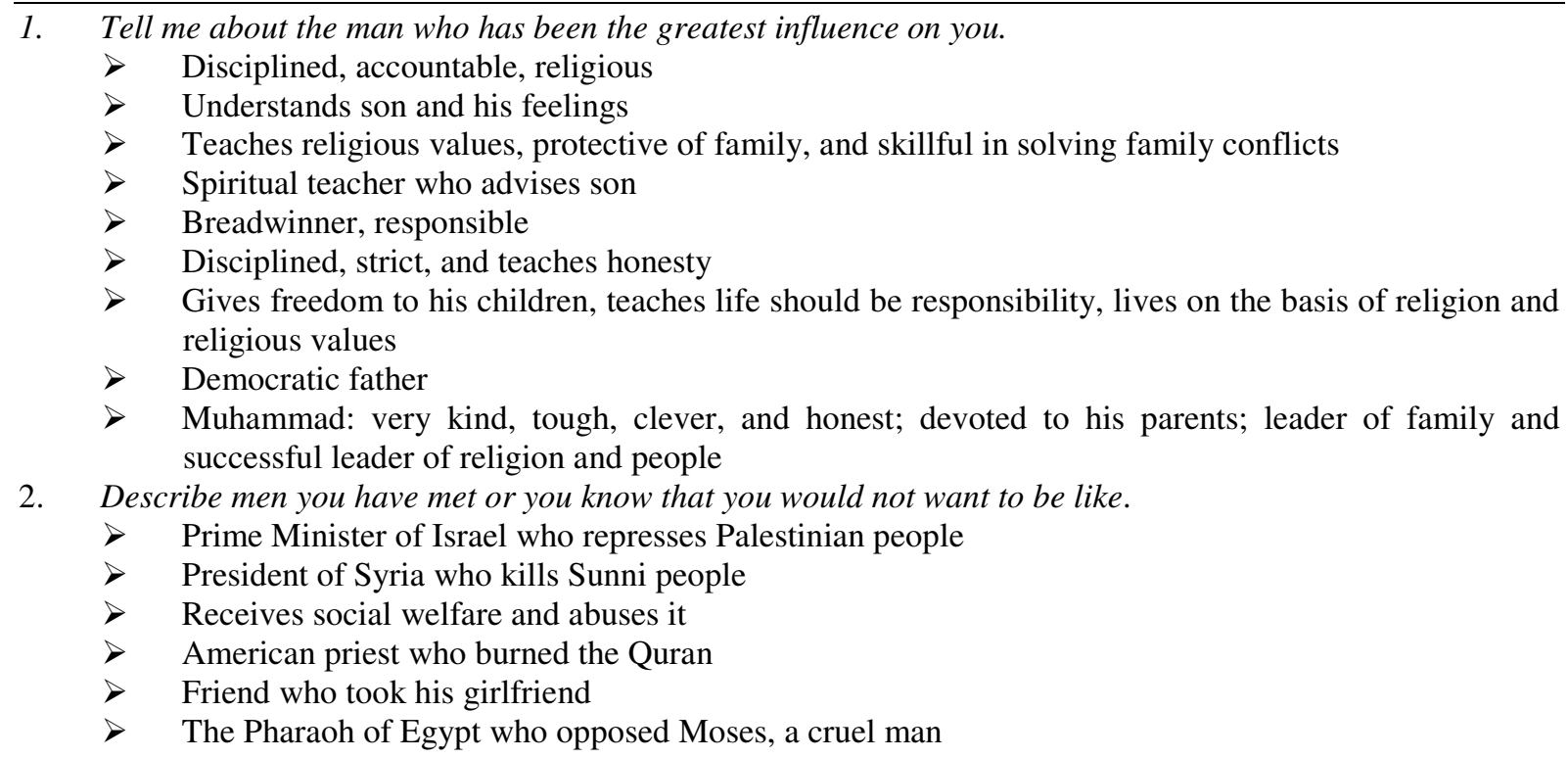


Wade, J. C., \& Wiloso, P. G.

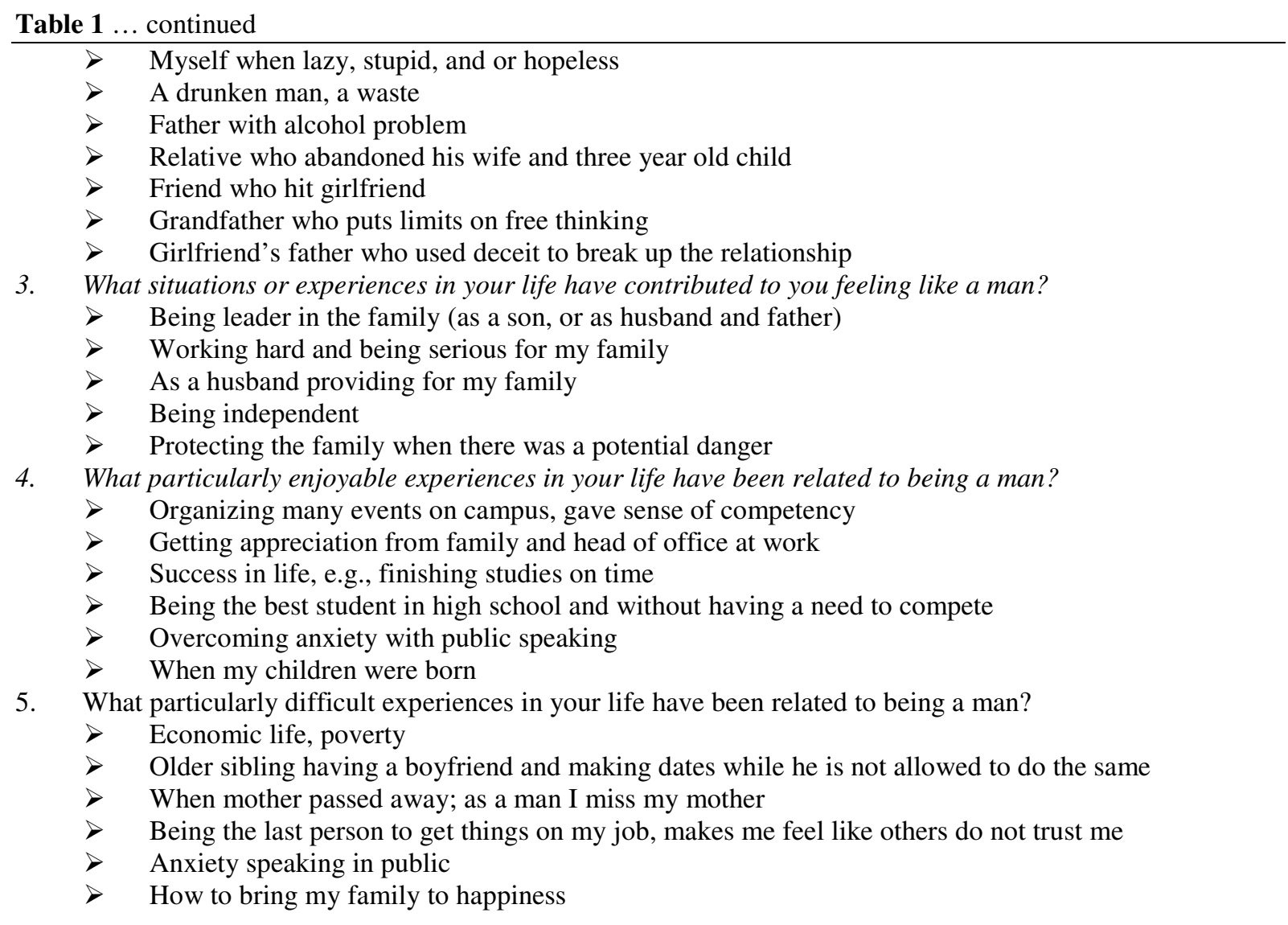

\section{Survey research}

\subsection{Participants}

Participants were 90 Javanese Muslim men with a mean age of 34.02 years $(S D=10.83)$. Sixty-four $(71.1 \%)$ were married, and nearly half $(49.4 \%)$ indicated their occupation as wiraswasta or pegawai swasta (i.e., private employer or private employee). Approximately $10 \%$ were students, and other occupations included teacher, construction, police officer, artist, and driver (each less than 6\%). Years married ranged from 6 months to 33 years with an average of 12.14 years $(S D=10.63)$. Of the 90 participants, 78 completed all measures (except the measure for marital satisfaction if not married). The 12 participants in the group interview had also completed the questionnaire except for the masculinity measure because it was developed after the group interview. Power analysis for a test of significance for correlation with power $=.80$, alpha $=.05$, and medium effect size indicated a sample of 85 participants was needed (Cohen, 1992).

\subsection{Measures}

All measures were translated into Indonesian using forward and back translation that involved three steps. First, forward translation was done by a web-based translation service. Next, a bilingual Javanese research assistant reviewed the Indonesian version for accuracy and performed back translation. The research assistant identified several words and concepts that were not comprehensible. Therefore, the researcher and assistant had to determine what words within the Indonesian language could best communicate the concept so it would be understood by the participants. Lastly, a second bilingual Javanese research assistant reviewed the measure for accuracy of the English to Indonesian translation comparing the original and back-translated versions for consistency between their meanings. Given many Javanese have some knowledge of the English language, each item was presented in Indonesian with the English version of the item directly underneath. In this way 
participants could choose to check the English translation of the item for their own understanding of what is being asked in Indonesian.

Masculinity Experiences Scale - The Masculinity Experiences Scale (MES) was developed to assess the importance of Javanese masculinity experiences. The construction of the MES was based on the Inventory of Subjective Masculinity Experiences (ISME) developed by Wong et al. (2011). A distinctive feature of the ISME is that it is a quantitative measure that is based on qualitative data. Dimensions of masculinity experiences are identified through a qualitative approach based on the number of times participants provide descriptions that fit the dimensions (Wong et al., 2011). The principal investigator used an analogous approach in developing the MES by analyzing the "As a man" responses from the group interview participants. First, the responses that were written in Indonesian were translated into English by the research assistant. Next, responses that were basically saying the same thing were evaluated and the one response that best represented the idea was selected. The remaining responses were then grouped together based on similarity of content. These responses were then analyzed for thematic representation. This procedure resulted in 36 items in four categories that formed the four subscales of the MES: Head of Family Responsibilities (12 items, e.g., be leader of family, provide solutions in the family, make the family happy, save family in world and hereafter, protect family members, work hard for family), Being Strong (10 items, e.g., be independent, do not despair, be strong, be brave, have determination), Constructive Relationships with Others (8 items, e.g., willing to sacrifice for love, honesty in relationships, respect others, be polite), and Constructive Mental Activity (6 items, e.g., think positive, be creative, use more logic than feelings, be smart).

Participants were given the following instructions: "Think about your personal experience of what it means to be a man and rate how important the following are to you as a man by giving the number 1, 2, 3, 4, or 5." The response scale provided the following anchors: $1=$ Not important, $3=$ somewhat important, $5=$ very important. High scores indicate that a particular MES dimension is a salient aspect of a man's masculinity experiences. Cronbach's alphas for the MES were as follows: Head of Family Responsibilities, .82; Being Strong, .81; Constructive Relationships with Others, .73; Constructive Mental Activity, .72; and MES total scale, .92.

Changing Gender Roles Scale - The Changing Gender Roles Scale (CGRS) is a measure developed for the purpose of the study to assess men's perceptions of changing gender roles. Participants were asked to respond to the items based on their experience over their lifetime. The first question asked participants to respond with Yes or No to the statement, "Men's and women's roles in Javanese society have been changing." If the response was No, they were told to not respond to the questions that followed and were directed to the next scale in the questionnaire. If the response was Yes, they were asked to respond to 6 items that asked about their beliefs and feelings about changes in men's and women's roles. The items were identical for men's roles and women's roles. The three basic items were as follows: "Ideals of masculinity (femininity) have changed for the better" (Also written in Indonesian and translated as "What it means to be a man/woman has changed for the better"), "I like how women's (men's) roles have changed," and "Javanese society has benefited by the changes in women's (men's) roles." Scale responses ranged from 1 (strongly disagree) to 6 (strongly agree). Cronbach's alpha in the current study was .80 . Higher scores indicate a more positive view of the changes in gender roles in Javanese society that have occurred in one's lifetime.

Religiosity Scale - The Religiosity Scale (RS) is a 6-item measure developed for the purpose of the study to assess the extent to which an individual is involved with their religion. Items were developed based on the Religious Commitment Inventory-10 (RCI-10; Worthington, Jr. et al., 2003) because the RCI-10 is a measure that can be used to assess religious commitment in diverse religious groups. Example items include "I make an effort to deepen my understanding of the rules and teachings of my religion," "I frequently share my religious values with my friends," and "I go to religious services and ceremonies." Participants respond to items using a 5-point Likert scale where $1=$ Never, $2=$ Rarely, $3=$ About half the time, $4=$ Usually, and $5=$ Always. Cronbach's alpha in the current study was .72. Higher scores indicate greater involvement in Islamic religion and religious practices. 
Wade, J. C., \& Wiloso, P. G.

Dyadic Satisfaction Scale - Married men completed the 7-item Dyadic Satisfaction Scale (DSS) of the Dyadic Adjustment Scale (DAS; Hunsley, Pinsent, Lefebvre, James-Tanner, \& Vito, 1995) that assesses feelings of positive and global contentment with the marital relationship. Respondents are asked to indicate the approximate extent of agreement or disagreement "between you and your wife" for each item. Scale responses range from 1 (Never or Almost Never) to 5 (All the time). Items were scored in the current study so that items reflecting negative satisfaction were reverse scored. As with the current study, the DSS had poor internal consistency reliability. Therefore, we used one item from the DSS to assess marital satisfaction, which was "Do you ever regret that you married?" Two items were selected to form a scale that assesses marital harmony, which were "How often do you and your wife quarrel?" and "How often do you and your wife get upset with each other?" Higher scores for these two measures indicate greater marital satisfaction and marital harmony respectively. The Cronbach's alpha for marital harmony was .78.

Demographic data - Participants were asked to provide the following information: age, religion, marital status, years married, and occupation. Each of these questions were asked using a blank line to fill in the response.

\subsection{Procedures}

The Javanese research assistant used the snowball sampling technique to recruit participants. He approached students and workers he knew from the university and within his neighborhood and told them about the research study being conducted by a visiting American professor. He explained the purpose of the study and asked if they would like to participate. Participants completed the questionnaire in the presence of the research assistant, so he could answer any questions they may have. After completing the questionnaire the participants were thanked for their participation and given 50,000 IDR (approximately \$5.00 USD). Additionally, the participant was asked to tell other Javanese Muslim men about the study and to contact the research assistant if they knew of others who wanted to participate.

\subsection{Results}

Descriptive statistics - Means and standard deviations for the measures are provided in Table 2. On average, the participants in this sample were "usually" involved in their religion and religious practices. They reported having high satisfaction in their marital relationships and high marital harmony. They "somewhat agree" that the changes in gender roles have been positive. All of the masculinity experiences were considered very important. $T$-tests indicated there were no significant differences between married and non-married participants on any of the measurement variables.

Table 2

Descriptive Statistics

\begin{tabular}{lcccc}
\hline & $\mathrm{N}$ & Mean & $S D$ & Possible Range \\
\hline Marital Satisfaction & 64 & 4.83 & .52 & $1-5$ \\
Marital Harmony & 64 & 7.27 & 1.36 & $2-10$ \\
Religiosity & 90 & 22.13 & 4.50 & $6-30$ \\
Changing Gender Roles & 77 & 22.96 & 5.43 & $6-36$ \\
MES Head of Family & 78 & 57.87 & 3.26 & $12-60$ \\
MES Being Strong & 78 & 45.78 & 4.25 & $10-50$ \\
MES Constructive Relations & 78 & 36.18 & 3.41 & $8-40$ \\
MES Constructive Mentality & 78 & 27.14 & 2.60 & $6-36$ \\
Total MES & 78 & 166.94 & 11.60 & $36-180$ \\
\hline Note. MES = Masculinity Experiences Scale. & & & &
\end{tabular}

Note. $\mathrm{MES}=$ Masculinity Experiences Scale.

Based on responses to the MES items, we identified the masculinity experiences with the highest percentages that were perceived as "very important." The items and the percentage of participants that responded with "very important" were as follows: Work hard for family (94.9), Protect family members (93.6), Be role model for family (91.0), Be leader of family (88.5), Guide family (88.5), Be able to make a living for family 
Religiosity, masculinity, and marital satisfaction among Javanese Muslim men

(87.2), Save family in world and hereafter (87.2), Make the family happy (85.9), Give good values to family (85.9). These 10 masculinity experiences were all items on the Head of Family Responsibilities subscale.

Correlational analyses - Research questions 2-5 were answered by correlational analyses. Correlations among the variables are provided in Table 3. Our second research question was, what is the relationship between men's perception of changing gender roles and their marital satisfaction? Of the 90 participants, 77 (85.6\%) answered "Yes" to the statement "Men's and women's roles in Javanese society have been changing." The CGRS did not significantly correlate with marital satisfaction or marital harmony. Separating men's roles from women's roles there was one positive correlation that approached significance for the relationship between marital harmony and perceiving the change in women's roles as positive, $r(52)=.21, p=.066$. Nonetheless, the findings indicate that men's perception of changes in gender roles was not associated with satisfaction with their marriage or marital harmony.

Table 3

Correlation Matrix

\begin{tabular}{|c|c|c|c|c|c|c|c|c|c|c|}
\hline & $\begin{array}{c}\text { Marital } \\
\text { Satisfaction }\end{array}$ & 2 & 3 & 4 & 5 & 6 & 7 & 8 & 9 & 10 \\
\hline 2. Marital Harmony & .20 & - & & & & & & & & \\
\hline 3. Changing Gender Roles & -.05 & .13 & - & & & & & & & \\
\hline 4. MES Total & $.35 * *$ & .10 & .01 & - & & & & & & \\
\hline 5. MES Head of Family & $.29 *$ & .11 & .00 & $.77 * *$ & - & & & & & \\
\hline 6. MES Being Strong & .19 & .11 & .01 & $.91 * *$ & $.58 * *$ & - & & & & \\
\hline 7. MES Relationships & $.39 * *$ & .13 & .00 & $.90 * *$ & $.58 * *$ & $.74 * *$ & - & & & \\
\hline 8. MES Mental Activity & $.36 * *$ & -.06 & .03 & $.83 * *$ & $.47 * *$ & $.71 * *$ & $.74 *$ & - & & \\
\hline 9. Religiosity & $.32 * *$ & $.21 *$ & -.05 & $.38 * *$ & $.33 * *$ & $.29 *$ & $.44 * *$ & $.26^{*}$ & - & \\
\hline 10. Age & .18 & .11 & $.29 *$ & .16 & .11 & .13 & .16 & .17 & .10 & - \\
\hline 11. Marital Status & - & - & $.20 *$ & .07 & .17 & -.02 & .05 & .07 & .12 & $.45 * *$ \\
\hline
\end{tabular}

The third research question was what is the relationship between masculinity and marital satisfaction? Marital satisfaction significantly positively correlated with Total MES, $r(58)=.35, p=.004$, and three of the subscales: Head of Family, $r(58)=.29, p=.014$, Constructive Relationships with Others, $r(58)=.39, p=.001$, and Constructive Mental Activity, $r(58)=.36, p=.003$. Marital Harmony did not significantly correlate with MES total score or the subscales. Thus, viewing the masculinity experiences as important was associated with being satisfied with one's marriage, though masculinity had no relationship to experiencing harmony in the marital relationship.

The fourth research question asked, what is the relationship between religiosity and men's marital satisfaction? The RS significantly positively correlated with marital satisfaction, $r(64)=.32, p=.005$, and marital harmony, $r(64)=.21, p=.048$. Therefore, being involved with Islamic religion was positively associated with marital satisfaction and marital harmony.

The fifth research question was what is the relationship between religiosity and masculinity? The RS significantly positively correlated with total MES score, $r(78)=.38, p<.001$, and the four subscales: Head of Family, $r(78)=.33, p=.002$, Being Strong, $r(78)=.29, p=.006$, Constructive Relationships with Others, $r(78)$ $=.44, p<.001$, and Constructive Mental Activity, $r(78)=.26, p=.01$. Thus, involvement in Javanese Islamic religion was positively associated with the importance of the masculinity experiences.

Regression analyses - Given the positive relationships between religiosity, masculinity, and marital satisfaction, we tested the mediational hypothesis that masculinity explains the positive relationship between religiosity and marital satisfaction (See Figure 2). As such, more religious men are more likely to view the masculinity experiences as important and thereby be satisfied with their marriage. We tested the mediation 
hypothesis using three regression equations (Baron \& Kenny, 1986), using mean substitution for missing values (i.e., 3 values across 2 cases). First masculinity was regressed on religiosity $(\beta=.33, t(58)=2.78, p=.007)$. Second, marital satisfaction was regressed on religiosity $(\beta=.32, t(58)=2.50, p=.015)$. Third, marital satisfaction was regressed on both masculinity $(\beta=.32, t(58)=2.32, p=.024)$ and religiosity $(\beta=.21, t(58)=$ $1.62, p=.111)$. In this regression equation that includes both masculinity and religiosity, the effect of religiosity on marital satisfaction is reduced (beta decreases from .32 to .21) and is no longer significant indicating full mediation. We conducted a test for the significance of the mediated effect using the Sobel test (Sobel, 1982), which confirmed the effect of masculinity on the relationship between religiosity and marital satisfaction $(z=$ $1.98, S E=.007, p=.047)$.

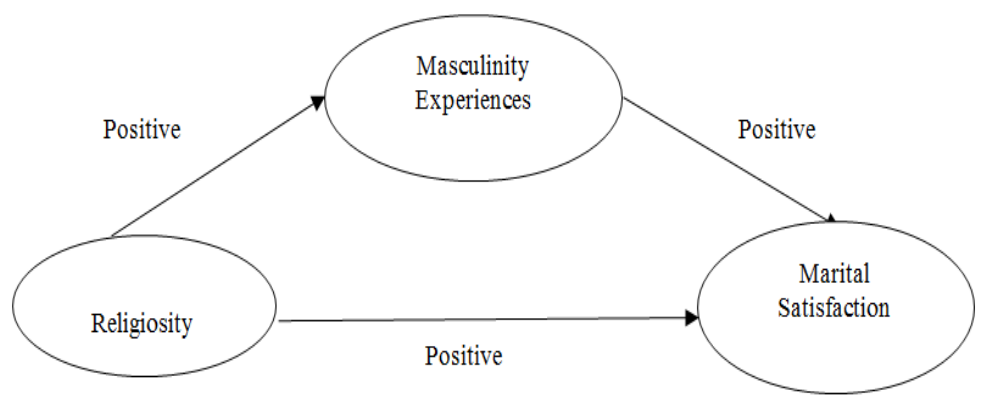

Figure 2. The mediating effect of masculinity experiences on the positive relationship between religiosity and marital satisfaction

\section{Discussion}

The purpose of this study was to discover how Javanese Muslim men's conceptions of masculinity, perception of the changes in gender roles, and religiosity relate to satisfaction in their marital life. This research was informed by the psychology of men and masculinity field that has made a significant contribution to understanding how traditional masculinity ideology in America as well as other countries can have negative consequences for men's lives. However, the approach taken in this research was one in which we wanted to discover how Javanese masculinity is configured and has positive consequences. Given the changes taking place in Indonesia with respect to women's emancipation, it was important to consider how religious continuity has been able contribute to men's marital satisfaction during these changes. To this end, we sought answers to several research questions through a sequential mixed-methods research methodology.

Eighty-six percent of the participants thought that gender roles have been changing in Java, and on average they felt that the change was positive. However, perception of changes in gender roles was not related to marital satisfaction or marital discord. Separating men's roles from women's roles there was one correlation that approached significance suggesting a positive relationship between marital harmony and perceiving the change in women's roles as positive. Given the small sample of men in this study, further investigation of this relationship in a larger sample of Javanese Muslim men is warranted.

The group interviews and "As a man" responses provided the data that was analyzed to discover how Javanese men define masculinity. There is no word in the Indonesian language for "masculinity." As such, participants were asked about manhood: what it means to be a man and what experiences are associated with being a man. There was congruence between Javanese cultural values and the masculine ideal. One's role and responsibilities within the family are important. Most answers to the interview questions were related to familial roles. Being a man means you are the leader of the family, which involves being the breadwinner and protector of the family, but also in a democratic and disciplined manner. Additionally, masculinity is associated with being independent, benevolent, honest, and reliable. Personal success defines manhood, but without the need for competition with others to have a feeling of achievement or success. 
Analysis of the "As a man" responses identified four areas that describe Javanese masculinity or manhood. Head of family responsibilities was the central masculinity experience that defines manhood. Such responsibilities include leading, guiding, providing for, and protecting the family. A man provides solutions and maintains discipline of household rules in the family. He is a role model and works hard for the family, and is responsible for their happiness and values. Manhood involves being strong, which means a man is independent, has determination, and never gives up. He is brave, takes risks, and faces his problems. A man has constructive relationships with others: he is honest and polite, respects others, understands people, doesn't break his promises, accepts criticism, and is willing to sacrifice for love. Lastly, certain aspects of manhood are considered constructive mental activity, such as improving oneself through learning, quick thinking, positive thinking, using logic, and being creative and smart.

The characteristics of Javanese masculinity coincide with the characteristics of positive masculinity in American culture as described by Kiselica, Benton-Wright, and Englar-Carlson (2015). In particular, the authors noted the characteristics of male ways of caring (caring for and protecting loved ones and friends), generative fatherhood (caring for and meeting children's needs), and worker-provider tradition (work to provide for loved ones) that are most consistent with the masculinity of Javanese men. Kiselica et al. defined positive masculinity as

"prosocial attitudes, beliefs, and behaviors of boys and men that produce positive consequences for self and others. These characteristics are not innate. Rather, they are learned and internalized through a socialization process in which boys and men develop masculine ways of thinking and behaving that promote healthy development while also fostering a sense of duty to others" (p. 126).

In this regard, our research showed Javanese masculinity was positively associated with marital satisfaction. In particular, the importance of head of the family responsibilities is consistent with the gender role norms of Javanese culture, and constructive relationships with others are consistent with the Javanese cultural value of harmony in social relationships. It may be the congruence between personal and cultural values that contributes to marital satisfaction among Javanese Muslim men.

There is no prior research that has examined psychosocial correlates of Javanese men's marital satisfaction. However, in a study of 25,847 married or cohabiting adults from 34 developed countries, both men and women in traditional relationships reported slightly higher family satisfaction on average, compared to respondents in non-traditional relationships (Forste \& Fox, 2012). Family satisfaction was similarly operationalized with one question that asked how satisfied the person was with their family life, and a traditional relationship was conceptualized as "man-breadwinner, woman-homemaker." These findings support how traditional gender roles in the family contribute to marital satisfaction in some cultures. However, Hayati et al.'s (2014) research that identified traditionalist, pragmatist, and egalitarian perspectives of masculinity begs the question of how these differing perspectives relate to marital satisfaction in Javanese Muslim men and women. The masculinity experiences identified as important to manhood in the present study are not representative of the more "traditionalist" views identified in Hayati et al.'s research. Within the group interviews and in the development of the Masculinity Experiences Scale, masculinity ideology was more consistent with the pragmatist and egalitarian perspectives.

Lastly, the results showed that involvement in Islamic religion and practices was positively associated with the importance of the masculinity experiences, marital satisfaction, and marital harmony. The finding that religiosity was associated with marital satisfaction is consistent with many studies that have examined this relationship (see Orathinkal \& Vansteenwegen, 2006). Given the significant positive associations among religiosity, masculinity, and marital satisfaction, we hypothesized that masculinity explains the relationship between religiosity and marital satisfaction; that is, more religious men would be more likely to view the masculinity experiences as important and thereby be more satisfied in their marital relationship. The results 
provided support for this hypothesis. How Javanese men view manhood is intimately tied to their religion, which is the foundation of their culture and its values. Congruence between religiosity and Javanese masculinity within Javanese Islamic culture contributes to men's marital satisfaction.

There are several limitations to this study that deserve mentioning. The sample size for the descriptive study was small, which makes generalizability of the results limited. Future research should consider using a larger sample size including participants from other areas of Java. The present study took place in the small city of Salatiga in Central Java. Additionally, although the individual responses in the group interview were translated, there is always something that is missed in the translation. Similarly, the translation for some of the items on the questionnaire may have not been clear to participants, which could affect the reliability of the measures (e.g., the measure for marital satisfaction). The measure of masculinity experiences assesses the importance of certain characteristics associated with manhood for oneself. They are also experiences that could be considered "positive." Future research could investigate masculinity from a normative perspective (i.e., something that should be lived up to), conformity to masculine norms, and/or those aspects of masculinity that are considered negative in order to uncover problematic aspects of masculinity. Lastly, most of the measures used in this study were developed for the purposes of this study and its unique population. Thus, there is little support for the validity of the new measures other than reliability.

Notwithstanding the above limitations, the present study is unique in being the only study to explore any of these constructs with a sample of Javanese Muslim men. The findings shed light on the positive aspects of Javanese Muslim men's conceptions of masculinity as they relate to men's' religiosity and marital satisfaction. The implications of the research for practice, learners, and teachers is in the knowledge gained about the intersectionality of religion and masculinity as they relate to men's marital satisfaction. It would be important for clinicians working with Javanese Muslim men to assess their masculinity ideology as it relates to marital satisfaction if there are problems in the marital relationship. Within the field of psychology, men and masculinity is an area of needed attention in order to understand men's issues. Additionally, given the changing gender roles in Indonesia this research provides knowledge about how it may not be the changing gender roles that are affecting men's marital satisfaction, rather men's religiosity and conceptions of manhood should be the focus of attention. However, given the rise in divorces initiated by women, our results only provide one side of the story on marital satisfaction. Future research would need to investigate if Javanese women's marital satisfaction is associated with Javanese men's masculinity ideology and religiosity as well.

Acknowledgements: This research was approved by the Fordham University Institutional Review Board (IRB) and the State Ministry of Research and Technology, Jakarta, Indonesia.

\section{References}

Adamson, C. (2007). Gendered anxieties: Islam, women's rights, and moral hierarchy in Java. Anthropological Quarterly, 80(1), 5-37. http://dx.doi.org/10.1353/anq.2007.0000

Albert, I., Trommsdorff, G., Mayer, B., \& Schwarz, B. (2005). Value of children in urban and rural Indonesia: Socio-demographic indicators, cultural aspects, and empirical findings. In G. Trommsdorff \& B. Nauck (Eds.), The value of children in cross-cultural perspective. Case studies from eight societies (pp. 171-207). Lengerich, Germany: Pabst Science.

Baron, R. M., \& Kenny, D. A. (1986). The moderator-mediator variable distinction in social psychological research: Conceptual, strategic, and statistical considerations. Journal of Personality and Social Psychology, 51, 1173-1182. http://dx.doi.org/10.1037/0022-3514.51.6.1173

Cammack, M., \& Heaton, T. B. (2011). Explaining the recent upturn in divorce in Indonesia: Developmental idealism and the effect of political change. Asian Journal of Social Science, 39(6), 776-796. http://dx.doi.org/10.1163/156853111X619229

Cammack, M., Bedner, A., \& van Huis, S. (2015, May). Democracy, human rights, and Islamic family law in 
Post-Soeharto Indonesia. New Middle Eastern Studies, 5. Retrieved from http://www.brismes.ac.uk/nmes/archives/1413

Clark, M. A. (2010). Maskulinitas: Culture, gender and politics in Indonesia. Victoria, Australia: Monash University Press.

Cohen, J. (1992). A power primer. Psychological Bulletin, 112, 155-159. http://dx.doi.org/10.1037/0033-2909.112.1.155

Fontana, A., \& Frey, J. H. (1994). Interviewing: The art of science. In N. K. Denzin \& Y. S. Lincoln (Eds.), Handbook of qualitative research (pp. 361-376). Thousand Oaks, CA: Sage Publications.

Forste, R., \& Fox, K. (2012). Household labor, gender roles, and family satisfaction: A cross-national comparison. Journal of Comparative Family Studies, 43(5), 613-631.

Garcia, M., Greenley, R., Martin-Onraët, V., \& Pollack, L. (2015). Women's workforce participation in Indonesia and Malaysia. Retrieved from https://elliott.gwu.edu/sites/elliott.gwu.edu/files/Nathan\%20Associates, \%20Inc.pdf

Hayati, E. N., Emmelin, M., \& Eriksson, M. (2014). "We no longer live in the old days": A qualitative study on the role of masculinity and religion for men's views on violence within marriage in rural Java, Indonesia. BMC Women's Health, 14, 58. Retrieved from http://www.biomedcentral.com/1472-6874/14/58 http://dx.doi.org/10.1186/1472-6874-14-58

Hunsley, J., Pinsent, C., Lefebvre, M., James-Tanner, S., \& Vito, D. (1995). Assessment of couples, marriages, and families. Construct validity of the short forms of the dyadic adjustment scale. Family Relations, 44, 231-237. http://dx.doi.org/10.2307/585520

IANS. (2009, February). Divorce rates jump in Indonesia after reforms. Thaindian News. Retrieved from http://www.thaindian.com/newsportal/uncategorized/divorce-rates-jump-in-indonesia-after-reforms_100 151476.html

Indonesia Database for Policy and Economic Research, World Bank. (2013). Total population (in number of people). Retrieved from http://knoema.com/WBINDDPER2015Jul/indonesia-database-for-policy-and-economic-research-indo-d apoer-world-bank-2013?location=1004240-salatiga-kota

Jones, G. W. (2015). Divorce trends and patterns in Asia. In S. R. Quah (Ed.), Routledge handbook of families in Asia (pp. 332-344). New York, NY: Routledge.

Kiselica, M. S., Benton-Wright, S., \& Englar-Carlson, M. (2015). Accentuating positive masculinity: A new foundation for the psychology of boys, men, and masculinity (pp. 123-143). In Y. J. Wong \& S. R. Wester (Eds.), APA Handbook of Men and Masculinities. Washington DC: American Psychological Association.

Kitzinger, J. (1994). The methodology of focus groups: The importance of interaction between research participants. Sociology of Health, 16(1), 103-21. http://dx.doi.org/10.1111/1467-9566.ep11347023

Law of the Republic of Indonesia Number 1 of the Year 1974 on Marriage. (1974). Retrieved from http://www.scribd.com/doc/53066173/Undang-undang-Republik-Indonesia-No-1-Tahun-1974-Tentangan\#scribd

Megawangi, R., Zeitlin, M. F., \& Colletta, N. D. (1995). The Javanese family. In M. F. Zeitlin, R. Megawangi, E. M. Kramer, N. D. Colletta, E. D. Babatunde, \& D. Garman (Eds.), Strengthening the family: Implications for international development (pp. 95-141). Tokyo: United Nations University.

Morgan, D. L. (1997). Focus groups as qualitative research. London: Sage. http://dx.doi.org/10.4135/9781412984287

Nwaba, A. (2014, November 30). Cross cultural similarities. Gender roles and expectations. Retrieved from https://gws350fall2014.wordpress.com/2014/11/30/cross-cultural-similarities/

Orathinkal, J., \& Vansteenwegen, A. (2006). Religiosity and marital satisfaction. Contemporary Family Therapy, 28, 497-504. http://dx.doi.org/10.1007/s10591-006-9020-0

Sobel, M. E. (1982). Asymptotic intervals for indirect effects in structural equations models. In S. Leinhart (Ed.), Sociological methodology (pp. 290-312). San Francisco: Jossey-Bass. http://dx.doi.org/10.2307/270723

Turner, S. (2002). Indonesia's small entrepreneurs: Trading on the margins. New York: Routledge. 
Wade, J. C., \& Wiloso, P. G.

Williams, W. L. (1991). Javanese lives: Women and men in modern Indonesian society. New Brunswick, NJ: Rutgers University Press.

Wirawan, B. M., \& Ratnaningsih, I. Z. (2011). Fathering in relation with father's educational level and occupation in Semarang-Central Java: Indigenous psychological approach. Retrieved from http://eprints.undip.ac.id/41841/1/Fathering.pdf

Wong, Y. J., Shea, M., LaFollette, J. R., Hickman, S. J., Cruz, N., \& Boghokian, T. (2011). The Inventory of Subjective Masculinity Experiences: Development and psychometric properties. Journal of Men's Studies, 19, 236-255. http://dx.doi.org/10.3149/jms.1903.236

Worthington, E. L., Jr., Wade, N. G., Hight, T. L., Ripley, J. S., McCullough, M. E., Berry, J. W., \& O’Connor, L. O. (2003). The Religious Commitment Inventory-10: Development, refinement, and validation of a brief scale for research and counseling. Journal of Counseling Psychology, 50(1), 84-96.

http://dx.doi.org/10.1037/0022-0167.50.1.84 